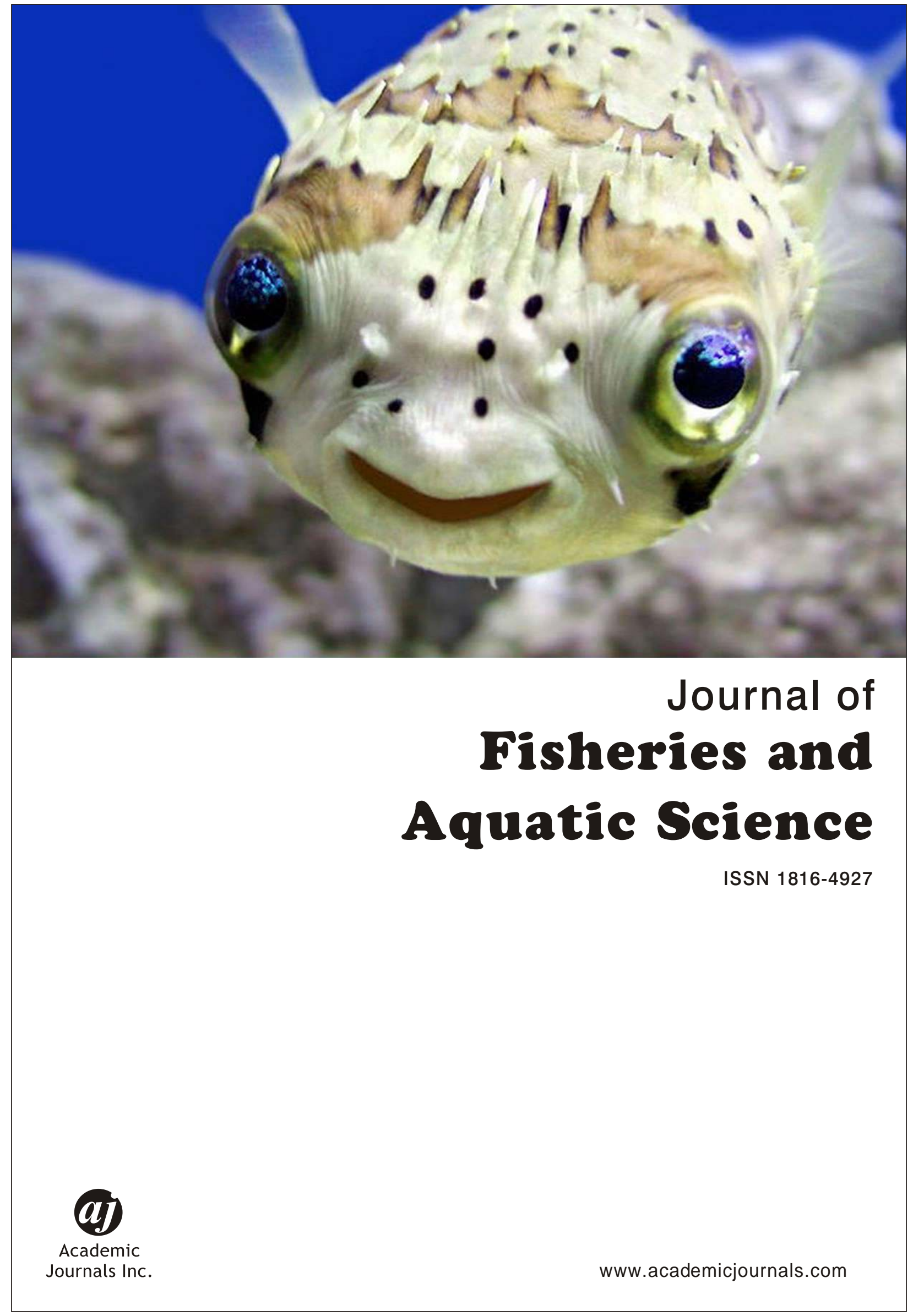


Journal of Fisheries and Aquatic Science 8 (6): 627-642, 2013

ISSN 1816-4927 / DOI: 10.3923/jfas.2013.627.642

(C) 2013 Academic Journals Inc.

\title{
Spawning Migration and Some Biological Aspects of Labeobarbus species in Infranz River, Lake Tana Sub Basin, Ethiopia
}

\author{
${ }^{1}$ Shewit Gebremedhin, ${ }^{1}$ Minwyelet Mingist and ${ }^{2}$ Brhanu Kebede \\ ${ }^{1}$ Department of Fisheries, Wetland and Wildlife Management, Bahir Dar University, P.O. Box 79, Bahir \\ Dar, Ethiopia \\ ${ }^{2}$ Department of Water Resource and Irrigation Management, Bahir Dar University, P.O. Box 79, Bahir Dar, \\ Ethiopia
}

Corresponding Author: Shewit Gebremedhin, Department of Fisheries, Wetland and Wildlife Management, Bahir Dar, University, P.O. Box 79, Bahir Dar, Ethiopia

\begin{abstract}
The main aim of the study is to investigate the spawning migration and some biological aspects of Labeobarbus species. Fish were sampled monthly in the non-peak spawning season and twice in the peak spawning season using gillnets and Monofilament. A total of 832 Labeobarbus specimens were collected from all sampling sites. Out of the total catch of Labeobarbus, the four dominant species contributed $83.0 \%$. Labeobarbus intermedius was the most dominant species in all sites but L. nedgia was the second in site 2 and 3. However, L. tsanensis and L. brevicephalus were the second dominant species in site 1 and 4, respectively. The peak spawning months for Labeobarbus species was from August to October. Length-weight relationship for all of the dominant species was curvilinear and statistically significant $(p<0.05)$. The chi-square test showed that there was significant difference between the number of females and males for L. intermedius and $L$. tsanensis. The average number of eggs for L. intermedius and L. brevicephalus was 9055 and 4312, respectively and the relationship of absolute fecundity with FL, was curvilinear, however, with TW and GW of the two species was linear and statistically significant $(\mathrm{p}<0.05)$. Labeobarbus intermedius and $L$. tsanensis were the first species to aggregate in the river mouth. However, Labeobarbus brevicephalus was the last species to aggregate. The first and the last migrant to upstream sites were L. intermedius and L. brevicephalus, respectively. Closing season should be strictly implemented during the spawning season from July to November.
\end{abstract}

Key words: Infranz river, closed season, condition factor, sex ratio, spatial and temporal segregation

\section{INTRODUCTION}

In Lake Tana there are three commercially important families of fish: Cichlidae, Clariidae and Cyprinidae.

According to Nelson (1994), Cyprinidae is one of the widespread and diverse family from all freshwater fish families and vertebrates. Labeobarbus species of Lake Tana are the only species in the world (Kornfield and Carpenter, 1984; Nagelkerke et al., 1994; Nagelkerke and Sibbing, 2000). Some Labeobarbus species migrates to the upstream of the tributaries to get suitable environment for spawning like gravel beds, fast flowing water with adequate oxygen.

In Lake Tana there are 15 Labeobarbus species which are biologically distinct and forms a unique species flock (Nagelkerke and Sibbing, 2000). 
The common evidences for the species status of Labeobarbus of Lake Tana are: their distinct morphometrics (Nagelkerke et al., 1994; Nagelkerke, 1997; Nagelkerke and Sibbing, 2000); their segregation in food niches (Nagelkerke et al., 1994; Nagelkerke, 1997; Sibbing and Nagelkerke, 2001; De Graaf et al., 2008); their spatial distribution patterns (Nagelkerke et al., 1994; De Graaf et al., 2008); the maximal body size they attain (Nagelkerke and Sibbing, 1996); different immuno-genetics (Dixon et al., 1996; Kruiswijk et al., 2002); and indications of spawning segregation (Nagelkerke and Sibbing, 1996; De Graaf, 2003; Palstra et al., 2004; De Graaf et al., 2005; Anteneh et al., 2008; Gebremedhin et al., 2012).

Different studies conducted in some tributary rivers of Lake Tana such as Gelgel Abay, Gelda and Gumara Rivers (Nagelkerke and Sibbing, 1996; Palstra et al., 2004; De Graaf et al., 2005) and Ribb, Dirma and Megech, Arno-Garno Rivers (Anteneh et al., 2008; Getahun et al., 2008; Gebremedhin et al., 2012) showed the upstream spawning migration of some Labeobarbus species. At least nine Labeobarbus species (L. acutirostris, L. brevicephalus, L. intermedius, L. macrophtalmus, L. megastoma, L. platydorsus, L. truttiformis L. tsanensis and L. nedgia) were reported as riverine spawners.

But the remaining six L. dainellii, L. surkis, L. gorgorensis, L. crassibarbis, L. gorguari and L. longissimus) were reported as missing. The probable assumptions are either they migrate to spawn in other unstudied tributary of Lake Tana such as Infraz River, or they might be lacustrine spawners (Nagelkerke and Sibbing, 1996; Palstra et al., 2004; De Graaf et al., 2005; Anteneh et al., 2008; Gebremedhin et al., 2012). However, which species of the Labeobarbus species migrate and at what time or seasons of the year do they migrate to Infranz River is not clearly known.

On the other hand Labeobarbus species are vulnerable to fishing activities as a result of their aggregation at the river mouths (De Graaf et al., 2004; De Graaf et al., 2006). The upstream spawning migrations of Lake Tana Labeobarbus species is highly influenced by the commercial gillnet fishery as gillnets are set near the river mouths. Hence, there is a dramatic decline ( $>75 \%$ in number) of the riverine spawners (De Graaf et al., 2004). Poisoning of the spawning stock using the crushed seeds of Birbira (Ameha, 2004) and alteration of the breeding and nursery grounds are the possible explanations for the decline of Labeobarbus stock. Infranz River is one of the unstudied rivers flowing into Lake Tana. Therefore, investigation of the Labeobarbus species migrating to Infranz River is very important for the rational exploitation and conservation of the unique species flock. Thus, the aim of this study was to investigate the spawning migration and some biological aspects of Labeobarbus species in Infranz River.

\section{MATERIALS AND METHODS}

Study area description: Lake Tana is the largest lake in Ethiopia with an area of about $3200 \mathrm{~km}^{2}$ and is situated in the north-western highlands at an altitude of about $1800 \mathrm{~m}$. The Lake is believed to have originated two million years ago by volcanic blocking of the Blue Nile River and it is the headwater of the Blue Nile River. It is shallow lake with an average depth of $8 \mathrm{~m}$ and maximum depth of $14 \mathrm{~m}$ and it is turbid, well-mixed and has no thermocline (Vijverberg et al., 2012) and it has a catchment area of $16,500 \mathrm{~km} 2$. Infranz River which is the tributary of Lake Tana is situated North west of Bahir Dar town, in the southern part of Lake Tana watershed in the district of Bahir Dar zuria woreda and western Gojam zone of the Amhara region (Fig. 1). At local level, this river is surrounded by three villages, namely: Yibab from the South, Waramit from the North and Chercher Wegels a from the West and its source of water is ground water (Gebrekidane, 


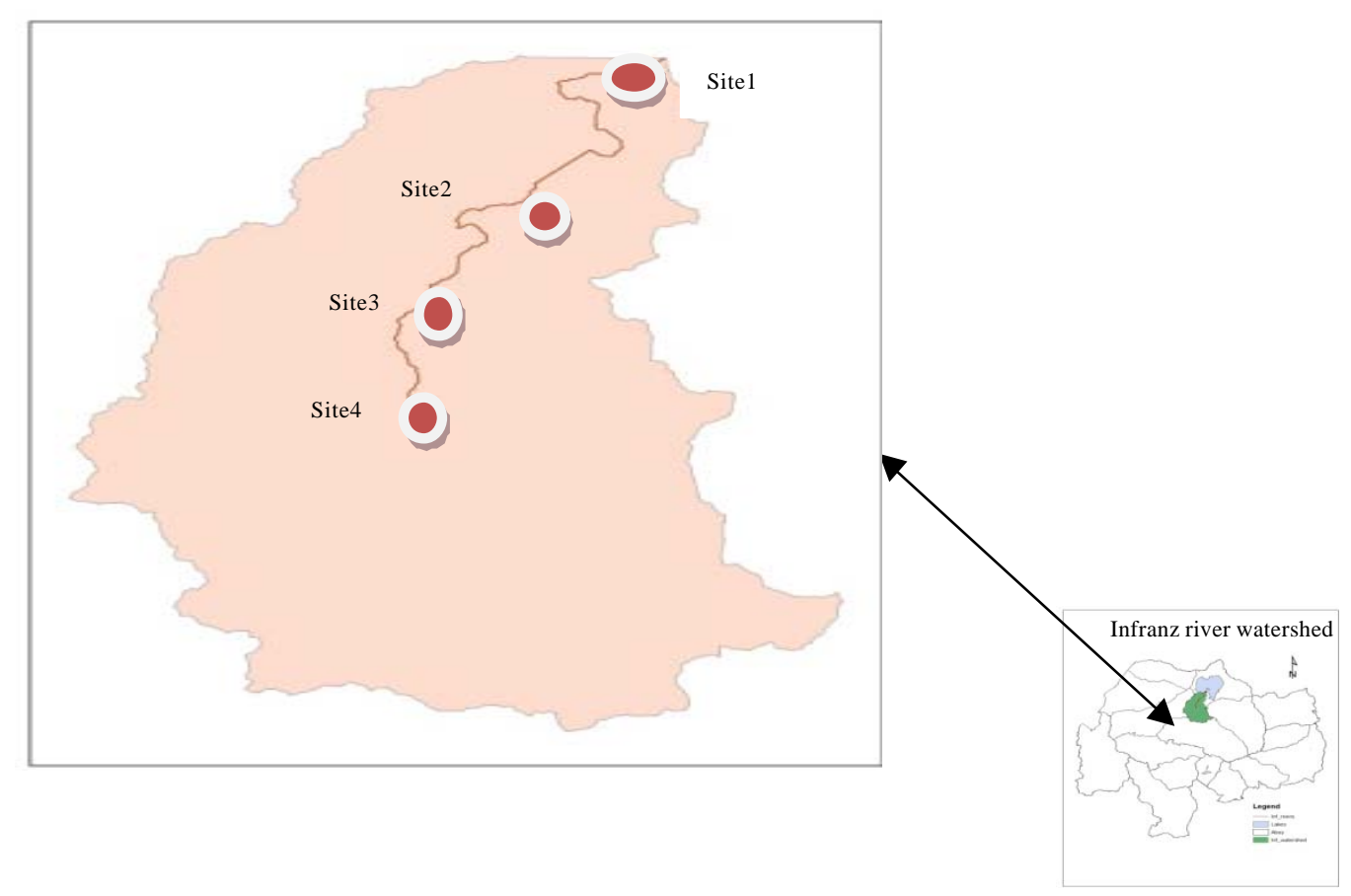

Fig. 1: Map of the study area

2010). The mean monthly temperature of this river is $17.5 \mathrm{oC}$, mean annual rainfall of $1437 \mathrm{~mm}$ with heavy rains during July-September and dry season during December-April (Gebrekidane, 2010).

\section{Data collection and sampling}

Field sampling: Four sampling sites based on the nature, velocity of the flowing river, human interference, suitability for fish spawning and availability of fishes were selected by preliminary assessment/survey and sampling sites were fixed using GPS. Fish samples were collected monthly in July and November, 2011. However, samples were collected twice per month from August to October 2011 at all selected sites of Infranz River. Gill nets of 6, 8, 10 and $14 \mathrm{~cm}$ stretched bar mesh, having a length of $25 \mathrm{~m}$ and depth of $1.5 \mathrm{~m}$ and monofilament were used to sample fish. Gill nets were set in the river mouth at a depth of 2.5-3.5 m overnight.

But in the upstream fish were sampled during day time since it is difficult to set gill nets overnight due to the usual heavy rainfall in the afternoon in the area. Fish were identified to species level using keys developed by Nagelkerke and Sibbing (2000). Some fish samples from each species were preserved in 5\% formalin solution and put in plastic jar and transported to the laboratory to serve as reference specimens. Then, fork length $(0.1 \mathrm{~cm})$, total weight $(0.1 \mathrm{~g})$ and gonad weight $(0.01 \mathrm{~g})$ of each specimen of Labeobarbus species were measured at the sampling sites. After dissection, gonad maturity of each fish specimen was identified using a seven-point maturity scale (Nagelkerke, 1997) and at the same time each fish was sexed. Samples of eggs from some ripe female Labeobarbus species having different fork lengths were preserved using $5 \%$ formalin solution for fecundity estimation. 
Abiotic factors: The physico-chemical parameters (water temperature, $\mathrm{pH}$, total dissolved solutes and conductivity) were measured in all sampling sites and time using conductivity meter. Water transparency (Secchi-depth) was measured using Secchi-disc.

Relative abundance: An Index of Relative Importance (IRI) was used to evaluate relative abundance. IRI is a measure of the relative abundance or commonness of the species based on number and weight of individuals in catches, as well as their frequency of occurrence (Kolding, 1989, 1999). IRI was used to find the most important species in terms of number, weight and frequency of occurrence in the catches from the different sampling localities. IRI gives a better representation of the ecological importance of species rather than the weight, numbers or frequency of occurrence alone (Sanyanga, 1996). Percent of IRI was calculated as follows:

$$
\operatorname{IRI}(\%)=\frac{\left(\mathrm{W}_{i}+N_{i}\right) \times F_{i}}{\sum_{j-1}^{S-1}\left(W_{j}+N_{i}\right) \times F_{j}} \times 100 \%
$$

where, $\mathrm{W}_{\mathrm{i}}$ and $\mathrm{N}_{\mathrm{i}} \%$ are percentage weight and number of each species of total catch respectively; $\mathrm{F}_{\mathrm{i}} \%$ is percentage frequency of occurrence of each species in total number of settings. $\mathrm{W}_{j}$ and $\mathrm{N}_{j} \%$ are percentage weight and number of total species of total catch, respectively. $\% \mathrm{~F}_{\mathrm{j}}$ is percentage frequency of occurrence of total species in total number of settings.

Length-weight relationship: The relationship between fork length and total weight of the dominant Labeobarbus species of the Infranz River were calculated using power function of $\mathrm{Tw}=\mathrm{aFL}^{\mathrm{b}}$ as in Bagenal and Tesch (1978). Where; $\mathrm{Tw}$ - total weight (g), FL- fork length (cm), a and $b$ are intercept and slope of regression line, respectively. The line fitted to the data was described by the regression equation for each species.

Condition Factor (Fulton's factor): The well-being of each dominant Labeobarbus species of the Infranz River was studied by using Fulton's condition factor (Bagenal and Tesch, 1978). Fulton's condition factor (\%) was calculated as:

$$
\mathrm{FCF}=\frac{\mathrm{TW}}{\mathrm{FL}^{3}} \times 100
$$

where, Tw- total weight (g) and FL- fork length (cm).

Sex-ratio: Sex ratio, is the proportion of females to males, was determined using this formula:

$$
\text { Sex ratio }=\frac{\text { No. of female }}{\text { No. of males }}
$$

Chi-square $\left(\chi^{2}\right)$ was used to test significant difference in sex ratios.

Gonado-somatic index (GSI): GSI is the ratio of fish gonad weight to body weight. The GSI was determined using the following formula Bagenal (1978): 


$$
\begin{aligned}
& \text { J. Fish. Aquat. Sci., } 8(6): 627-642,2013 \\
& \text { GSI (\%) }=\frac{\text { Gonadweight }(\mathrm{g})}{\text { Bodyweight }(\mathrm{g})} \times 100
\end{aligned}
$$

Fecundity: Fecundity is the number of eggs in ovary before spawning and it was estimated using gravimetric method (MacGregor, 1957) by weighing all the eggs from each of the ovaries of gravid fish species. Samples of eggs were taken from different size classes of each fish species on various ovary areas. These eggs were preserved in a labeled plastic bag containing $5 \%$ formalin solution for fecundity estimation (Bagenal, 1978). After ovarian membranes were removed mechanically using tap water from the preserved ovaries, eggs were counted. Three sub-samples of $1 \mathrm{~g}$ eggs were taken from different parts of ovary and counted and the average was calculated.

The total number of eggs per ovary was calculated by extrapolation from the mean calculated. The correlation of fecundity with total length, total weight and ovary weight were done to determine the relationship of fecundity with morphometrics measurements. This was done according to this formula:

$$
\mathrm{F}=\mathrm{aFL} ; \mathrm{F}=\mathrm{aTw}^{\mathrm{b}} \text { and } \mathrm{F}=\mathrm{a} \mathrm{GW}^{\mathrm{b}}
$$

where, F-Fecundity; FL-Fork length (cm); Tw- Total weight (g); GW- Gonad weight; a- constant and b- exponent.

Data analysis: SPSS version 16 software and Microsoft office Excel 2007 were used to analyze and manage the data. One-way ANOVA was used to analyze length weight relationship, Fulton's condition factor, abiotic parameters and spatial and temporal segregation.

\section{RESULTS AND DISCUSSION}

Physico-chemical parameters: Physical and chemical parameters such as temperature, $\mathrm{pH}$, TDS, conductivity and water transparency (secchi depth) from all sampling sites were analyzed using one way ANOVA and there was no significant difference ( $p>0.05$ ) except for sechi depth (64.65 \pm 9.09 ) at all sampling sites (Table 1). However, water transparency (secchi depth) showed significant variation $(p<0.05)$ between the sampling sites. As it is tested using LSD the mean of secchi depth of site $1(17.44 \pm 6.33)$ showed significant variation $(p<0.01)$ with means of site 3

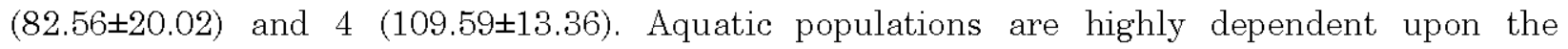
characteristics of the aquatic habitat, which supports all their biological functions (reproduction, growth, feeding and sexual maturation).

Thus, abiotic factors are the controlling factors for the aquatic life, since they shape most of the biological functions of aquatic life (Murdoch and Martha, 1999). Cyprinids (e.g., Labeobarbus) as

Table 1: Mean \pm Std. error of the abiotic parameters in all of the sampling sites

\begin{tabular}{lcllcc}
\hline Site & Temperature $\left({ }^{\circ} \mathrm{C}\right)$ & $\mathrm{pH}$ & TDS $(\mathrm{ppm})$ & ${\text { Conductivity }\left(\mu \mathrm{s} \mathrm{cm}{ }^{-1}\right)}^{\text {Secchi depth }(\mathrm{cm})}$ \\
\hline 1 & $22.56 \pm 0.82^{\text {ns }}$ & $6.33 \pm 0.37^{\mathrm{ns}}$ & $82.22 \pm 11.40^{\mathrm{ns}}$ & $160.34 \pm 23.33^{\mathrm{ns}}$ & $17.44 \pm 6.33^{*}$ \\
2 & $22.22 \pm 0.70^{\mathrm{ns}}$ & $6.56 \pm 0.18^{\mathrm{ns}}$ & $94.22 \pm 6.94^{\mathrm{ns}}$ & $189.33 \pm 13.55^{\mathrm{ns}}$ & $49.00 \pm 15.02^{*}$ \\
3 & $19.89 \pm 1.02^{\mathrm{ns}}$ & $6.89 \pm 0.20^{\mathrm{ns}}$ & $86.11 \pm 6.12^{\mathrm{ns}}$ & $173.47 \pm 12.23^{\mathrm{ns}}$ & $82.56 \pm 20.02^{*}$ \\
4 & $22.13 \pm 0.56^{\mathrm{ns}}$ & $6.72 \pm 0.22^{\mathrm{ns}}$ & $97.89 \pm 4.54^{\mathrm{ns}}$ & $189.66 \pm 6.54^{\mathrm{ns}}$ & $109.59 \pm 13.36^{*}$ \\
Average & $21.70 \pm 0.42$ & $6.62 \pm 0.13$ & $90.11 \pm 3.82$ & $178.20 \pm 7.54$ & $64.65 \pm 9.09$ \\
\hline
\end{tabular}

*Significant at $\mathrm{p}=0.001$, ns: Not significant, Values are presented as Mean $\pm \mathrm{EE}$. Number of observation for all of the parameter is 8 
they lack parental care, fast flowing, clear and highly oxygenated water and gravel-bed streams or rivers are generally their spawning ground requirements. The gravel or pebble beds protect their eggs from being washed away by riffle and clear water will not cover their eggs with a film of sediment obstructing the diffusion of oxygen (Lowe-McConnell, 1975).

Infranz River serves as a best spawning area for Labeobarbus species since it has fast flowing, clear and gravel beds and absence of clear waterfalls that affect fish migration. The variation in mean secchi depth of site 1 with site 3 and 4 might be due to the fact that the river mouth gets more turbid due to sediment deposition from various sources. The $\mathrm{pH}$ value of the River was almost neutral at all sampling sites. A similar observation was made by Anteneh et al. (2008) in Megech and Dirma Rivers and Gebremedhin et al., 2012 in Arno-Garno River which are thought to be ideal breeding ground for the Labeobarbus species of Lake Tana. The average conductivity and TDS of Infranz River were in line with Gebremedhin et al. (2012) in Arno-Garno River.

Relative abundance: Relative abundance is a measure of the relative commonness of the species based on number and weight of individuals in catches, as well as their frequency of occurrence (Kolding, 1989, 1999). Hence, the species composition of gillnet catch from all of the sampling sites at Infranz River were ranked based on the Index of Relative Importance (IRI) (Table 2). Labeobarbus intermedius was the most abundant species at all sampling sites (i.e., 47, 67, 48 and $70 \%$ in site 1 to 4, respectively). Except at site one (31\%) and four (14\%), in which L. tsanensis and L. brevicephalus were abundant, L. nedgia was the second most abundant species at site 2 (19\%) and site 3 (25\%). For L. intermedius similar results were reported by Gebremedhin et al. (2012) in Arno-Garno River and Anteneh et al. (2008) in Dirma and Megech Rivers.

Table 2: Percentage IRI of Labeobarbus species in Infranz River in all of the sampling sites

\begin{tabular}{|c|c|c|c|c|c|c|c|c|c|}
\hline Site & Species & TW (g) & TW (\%) & $\mathrm{N}$ & N (\%) & $\mathrm{F}$ & F (\%) & IRI & IRI (\%) \\
\hline \multirow[t]{5}{*}{1} & L. intermedius & 11430.9 & 46 & 66 & 46 & 4 & 80 & 7377 & 47 \\
\hline & L. brevicephalus & 1201.6 & 5 & 15 & 10 & 3 & 60 & 920 & 6 \\
\hline & L. nedgia & 3447.2 & 14 & 26 & 18 & 4 & 80 & 2566 & 16 \\
\hline & L. tsanensis & 8738.7 & 35 & 36 & 25 & 4 & 80 & 4831 & 31 \\
\hline & Total & 24818.4 & & 143 & & 5 & & 1569 & 3.38 \\
\hline \multirow[t]{5}{*}{2} & L. intermedius & 12178.5 & 56 & 71 & 47 & 5 & 100 & 10278 & 67 \\
\hline & L. brevicephalus & 3013.9 & 14 & 33 & 22 & 2 & 40 & 1426 & 9 \\
\hline & L. nedgia & 5140.1 & 24 & 37 & 25 & 3 & 60 & 2882 & 19 \\
\hline & L. tsanensis & 1424.8 & 7 & 10 & 7 & 3 & 60 & 789 & 5 \\
\hline & Total & 21839.6 & & 151 & & 5 & & 15376 & \\
\hline \multirow[t]{5}{*}{3} & L. intermedius & 11307.5 & 46 & 85 & 42 & 4 & 80 & 6992 & 48 \\
\hline & L. brevicephalus & 5536.5 & 22 & 63 & 31 & 3 & 60 & 3197 & 22 \\
\hline & L. nedgia & 5996.2 & 24 & 43 & 21 & 4 & 80 & 3627 & 25 \\
\hline & L. $t$ sanensis & 1622.7 & 7 & 13 & 6 & 3 & 60 & 776 & 5 \\
\hline & Total & 24722.9 & & 204 & & 5 & & 14592 & \\
\hline \multirow[t]{5}{*}{4} & L. intermedius & 14701.1 & 61 & 106 & 56 & 5 & 100 & 11668.1 & 70 \\
\hline & L. brevicephalus & 4095.2 & 17 & 41 & 22 & 3 & 60 & 2314.386 & 14 \\
\hline & L. nedgia & 3375 & 14 & 26 & 14 & 3 & 60 & 1660.08 & 10 \\
\hline & L. $t$ sanensis & 2089.4 & 9 & 16 & 8 & 3 & 60 & 1024.673 & 6 \\
\hline & Total & 24260.7 & & 189 & & 5 & & 16667.24 & \\
\hline
\end{tabular}


Length-weight relationship: Total Weight of the four dominant Labeobarbus species showed curvilinear relationship with Fork Length $(F L)$ and was statistically significant $(p<0.001$ ) (one-way ANOVA) and the line fitted to the data was described by the regression equation (Fig. 2). The regression coefficients for most of the dominant species were near to the cube value $(b=3)$.

In agreement with Anteneh et al. (2008) at Megech and Dirma Rivers, Nagelkerke et al., 1994 in Lake Tana and Gebremedhin et al. (2012) at Arno-Garno River, most of the dominant Labeobarbus species showed nearly isometric growth.

Fulton's condition factor: Fulton's condition factor for the dominant Labeobarbus species (L. intermedius, L. brevicephalus, L. nedgia and $L$. tsanensis) both by sex and spawning season in Infranz River was done. The mean Fulton's Condition Factor for L. intermedius and L. brevicephalus, was higher during the peak spawning months (August to October) than the nonpeak spawning months (July and November), however, it was lower for L. nedgia and L. tsanensis. Fulton's condition factor for L. intermedius, L. brevicephalus, L. nedgia and L. tsanensis migrating to Infranz River was not showed significant variation during the peak spawning months (August to October) and non-peak spawning months (July and November) with an average of $1.27 \pm .008,0.13 \pm .010,1.26 \pm .013$ and $1.35 \pm .014$ mean and standard error, respectively (one way ANOVA, p>0.05), (Table 3). Similar result was reported by Gebremedhin et al. (2012) for L. brevicephalus at Arno-Garno River. However, results obtained in Megech and Dirma Rivers (Anteneh et al., 2008) and Gebremedhin et al. (2012) indicated FCF was significantly different during the peak spawning months and non-peak spawning months. This difference might be due to the difference in size and source of water between the rivers.

Fulton conditions factor of those females and males of L. intermedius, L. brevicephalus, $L$. nedgia and L. tsanensis migrating to Infranz River with average mean and standard error of $1.27 \pm .007,1.22 \pm 0.010,1.26 \pm .014$ and $1.35 \pm .015$, respectively didn't show significant variation during the spawning season July to November ( $>0.05$ ) (Table 4). However, results obtained in
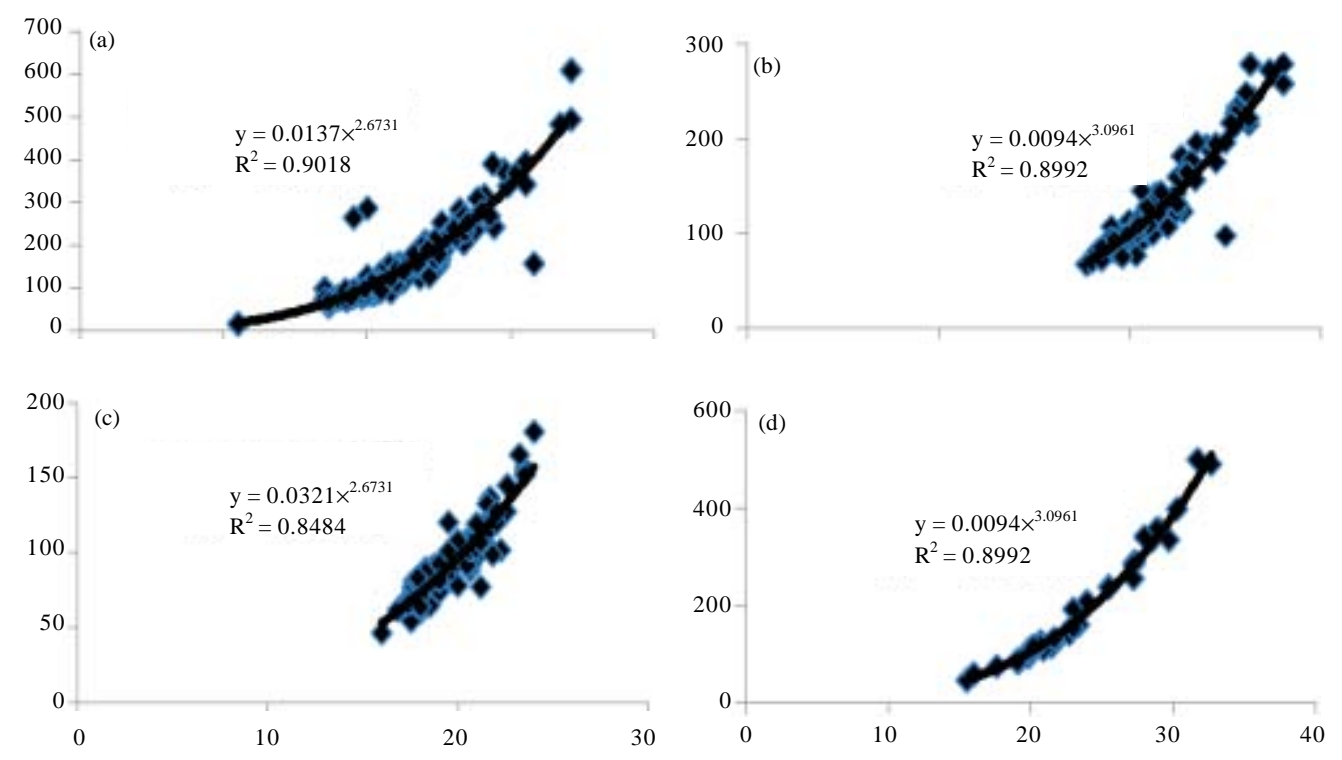

Fig. 2(a-d): Length-weight relationship of the four dominant Labeobarbus species migrating to Infranz River 
J. Fish. Aquat. Sci., 8(6): 627-642, 2013

Table 3: Mean $\pm \mathrm{SE}$ of Fulton's condition factor for the most dominant Labeobarbus species migrating to Infranz River by season, $\mathrm{N}$ is sample size, (one way ANOVA)

\begin{tabular}{llrccc}
\hline Species & Months & $\mathrm{N}$ & Mean & Std. Error & Sig. \\
\hline L. intermedius & Peak spawning & 271 & 1.2756 & 0.00902 & 0.562 \\
& Non-peak spawning & 57 & 1.2632 & 0.01884 & 0.00814 \\
& Total & 328 & 1.2735 & 0.01070 & 0.03291 \\
L. brevicephalus & Peak spawning & 138 & 0.12573 & 0.01018 & 0.289 \\
& Non-peak spawning & 14 & 0.12315 & 0.01413 & 0.02658 \\
L. nedgia & Total & 152 & 0.12557 & 0.01270 & 0.753 \\
& Peak spawning & 114 & 1.2605 & 0.01487 & 0.04738 \\
L. tsanensis & Non-peak spawning & 18 & 1.2722 & 0.01412 \\
& Total & 132 & 1.2621 & 1.3441 & 0.577 \\
& Peak spawning & 68 & 1.3714 & 1.3467 & 0 \\
\hline
\end{tabular}

Table 4: Mean $\pm \mathrm{SE}$ of Fulton's condition factor for the most dominant Labeobarbus species in Infranz River by sex. $\mathrm{N}$ is sample size (one way ANOVA)

\begin{tabular}{llcccc}
\hline Species & Sex & $\mathrm{N}$ & Mean & Std. Error & Sig. \\
\hline L. intermedius & Male & 125 & 1.2784 & 0.01253 & 0.01026 \\
& Female & 197 & 1.2685 & 0.00793 \\
& Total & 322 & 1.2724 & 0.01716 & 0.681 \\
L. brevicephalus & Male & 67 & 1.2104 & 0.01236 \\
& Female & 79 & 1.2190 & 0.01030 \\
L. nedgia & Total & 146 & 1.2151 & 0.02045 & 0.01817 \\
& Male & 53 & 1.2472 & 0.01356 \\
L. tsanensis & Female & 70 & 1.2671 & 0.02688 \\
& Total & 123 & 1.2585 & 0.01729 \\
& Male & 27 & 1.3519 & 0.866 \\
\end{tabular}

Megech and Dirma Rivers by Anteneh et al. (2008) and in Arno-Garno River Gebremedhin et al. (2012) showed significant variation of Fulton's condition factor between females and males of the dominant Labeobarbus species.

Sex ratio: From the total catch of 832 Labeobarbus species migrating to Infranz River in the study period, 50\% were females and 35\% were males, whereas the remaining $15 \%$ were unsexed. Generally, females were more numerous than males and the variation was higher during peak spawning season. The chi-square test showed that there was significant difference between the number of females and males for L. intermedius (1.6:1) and $L$. tsanensis (1.7:1) in Infranz River $\left(\chi^{2}, p<0.05\right)$, however, it was not significantly different for $L$. brevicephalus and L. nedgia $\left(\chi^{2}, p>0.05\right)$ from the theoretical 1:1 ratio (Table 5).

There are different reasons for the difference in sex ratio. For example, different biological mechanisms such as differential maturity rates, differential mortality rates and differential migratory rates between the male and female sexes may cause unequal sex ratios (Sadovy and Shapiro, 1987; Matsuyama et al., 1988). In addition to this, Al-kholy (1972) reported females of cyprinid Putius barberinus in Lake Lanao live longer time in the spawning areas than males. 
Table 5: Number of males, females, $\chi^{2}$ values and the corresponding sex ratios of the Labeobarbus species in infranz river (pooled data from all sampling sites)

\begin{tabular}{lccccc}
\hline Species & Female & Male & Sex ratio (Female:Male) & Chi-square & Asymp. Sig. \\
\hline L. intermedius & 198 & 124 & $1.6: 1$ & $17.006^{\mathrm{a}}$ & $0.000^{* * *}$ \\
L. brevicephalus & 79 & 67 & $1.2: 1$ & $0.986^{\mathrm{a}}$ & $0.321^{\mathrm{ns}}$ \\
L. nedgia & 70 & 53 & $1.3: 1$ & $2.350^{\mathrm{a}}$ & $0.125^{\mathrm{ns}}$ \\
L. tsanensis & 45 & 27 & $1.7: 1$ & $4.500^{\mathrm{a}}$ & $0.034^{*}$ \\
\hline
\end{tabular}

ns: Not significant: *significant: ***very strongly significant
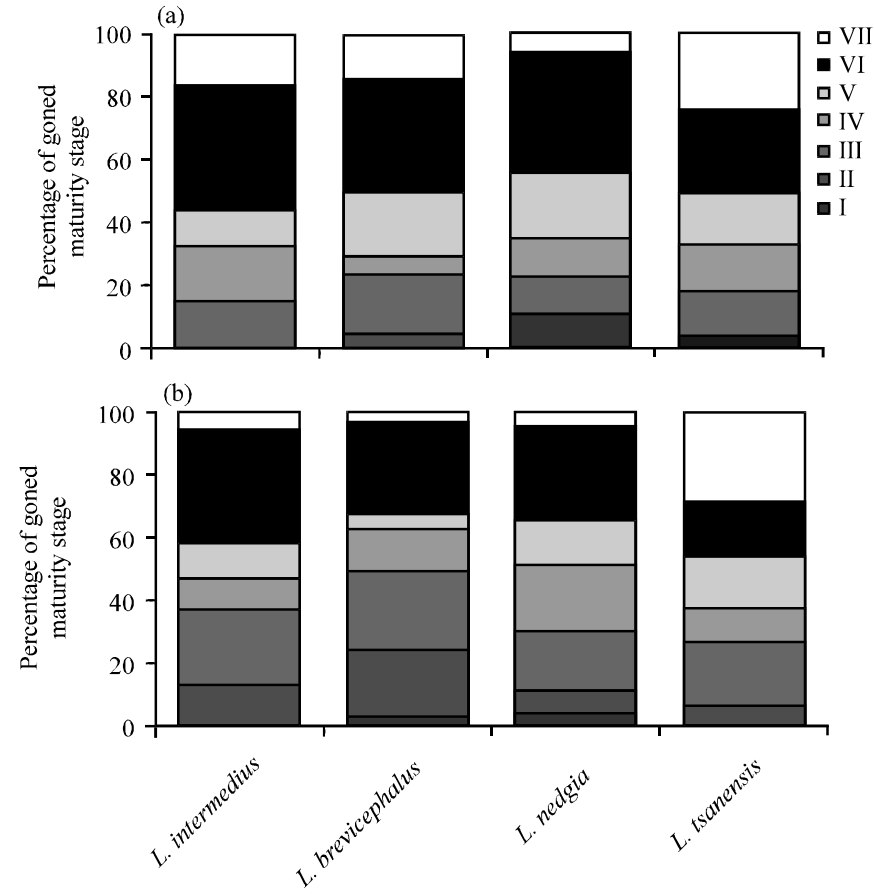

Fig. 3(a-b): Proportion of gonad maturity stages (I to VII) of the most dominant Labeobarbus species during peak spawning season (July to November) in the (a) River mouth (b) Upstream areas in Infranz River

Hence, living longer time in spawning areas and increased ovarian development as suggested by Taylor and Villoso (1994) may also cause the deviation from 1:1 sex ratio. Similar results were obtained for other cyprinid fishes like Labeo horie in Lake Chamo (Dadebo et al., 2003), Carassius carassius in Lake Ziway (Hirpo, 2012), Labeobarbus species in Megech and Dirma Rivers (Anteneh et al., 2008) and Gebremedhin et al. (2012) for those Labeobarbus species migrating to Arno-Garno River. Therefore, some of the above factors or combination of them might be the cause for the sex ratio variations of Labeobarbus species migrating to Infranz River.

Gonado somatic index (GSI): The gonad proportion of mature dominant Labeobarbus species in Infranz River (gonad stage IV and V), running (gonad stage VI) and spent (gonad stage VII) together was higher (about 64\%) than the immature gonads (gonad stages I-III, 36\%) in the samples collected during the spawning season (August to November) (Fig. 3).

From the total catch of the dominant Labeobarbus species in Infranz River, nineteen were caught with spent gonads ( 3 in river mouth i.e. one male and 2 female and 16 in upstream sites i.e. 
2 male and 14 female) and they were numerous at the end of October. From the total catch of specimens with spent gonad $L$. intermedius and $L$. brevicephalus were represented by 11 and 5 specimens each, 1 and 2 in the river mouth and 10 and 4 in the upstream sites, respectively. Labeobarbus nedgia was represented by 3 specimens all in the upstream areas. As it is clearly illustrated in Fig. 3, in the river mouth fish specimens with gonad stage $\mathrm{V}$ was dominant, whereas, in the upstream areas gonad stage VI was the dominant. Hence this is a good indication for the species aggregation in the river mouth as well as their migration to the upstream areas.

Fecundity: Information about fecundity of Barbus species in Africa is limited (Marshal, 1995). The few data on the fecundity of Labeobarbus species in Lake Tana and its tributaries are from the recent studies by Alekseyev et al. (1996), Anteneh et al. (2008) and Gebremedhin et al. (2012). Fecundity of the most dominant Labeobarbus species (L. intermedius and L. brevicephalus) was done from the total sample taken from Infranz River. Labeobarbus intermedius with fork length of 18.2 to $34.2 \mathrm{~cm}$, Mean $\pm \mathrm{SE}$ of $22.95 \pm 0.68$ had absolute (total) fecundity ranged from 1122 to 24506 and average fecundity was about 9055. Labeobarbus brevicephalus with fork length of 18.3 to $27.3 \mathrm{~cm}$, Mean $\pm \mathrm{SE}$ of $22.39 \pm 0.58 \mathrm{had}$ absolute fecundity ranged from 574 to 16073 and average fecundity was about 4312. Many researchers Anteneh et al. (2008) in Megech and Dirma Rivers, Tessema et al. (2012) in Borkena and Mille Rivers and Gebremedhin et al., 2012 was reported the average fecundity for L. intermedius. The result from this study was relatively higher than these reports. This difference might be due to the difference in size at maturity stages or the difference in environment.

Skelton et al. (1991) also reported the fecundity of Labeobarbus in other African lakes and it is moderately higher than from the reports in Lake Tana. For example, a female Labeo aeneus with $30 \mathrm{~cm}$ fork length in Vaal-orange River drainage system carries about 30,000 eggs on average (Berie, 2007) whereas L. intermedius in Infranz River with fork length of $34.2 \mathrm{~cm}$ carries about 9055 eggs on average. This might be related to environmental problems. Oliva-Paterna et al. (2002) also reported that fast growth, high fecundity and early maturity are the characteristics of unstable environments.

The relationship of Absolute Fecundity (AF) with FL, was curvilinear, however, AF with TW and GW of the two species was linear (Fig. 4, 5). There was strong relationship between AF and FL, TW and GW in both the L. intermedius and L. brevicephalus species (one way ANOVA, $\mathrm{p}<0.05$ ). in line with studies conducted in Gelda and Gumara Rivers Alekseyev et al. (1996), Borkena and Mille Rivers (Tessema et al., 2012) and Arno-Garno River, the fecundity of L. intermedius was strongly and positively correlated with its gonad weight, fork length and body weight.

\section{Segregation of Labeobarbus spp. in Infranz River}

Spatial segregation: All of the abundant Labeobarbus species migrating to Infranz River were found in the entire sampling site, though there is difference in proportion. The relative contribution of the most dominant Labeobarbus species within the sampling site is illustrated in Fig. 6 Labeobarbus intermedius was equally abundant in site, 1, 2 and 3 but it was relatively higher in site 4. Labeobarbus brevicephalus was abundant in site 3 and it was less abundant in site 1. Labeobarbus nedgia was almost all equally abundant in all sites. However, L. tsanensis was similarly distributed in site 2, 3, 4 and it was higher in site 1 . There was no significant difference in the distribution patterns of the four most abundant species of Labeobarbus over the four sampling sites in Infranz River (one-way ANOVA, p>0.05). 

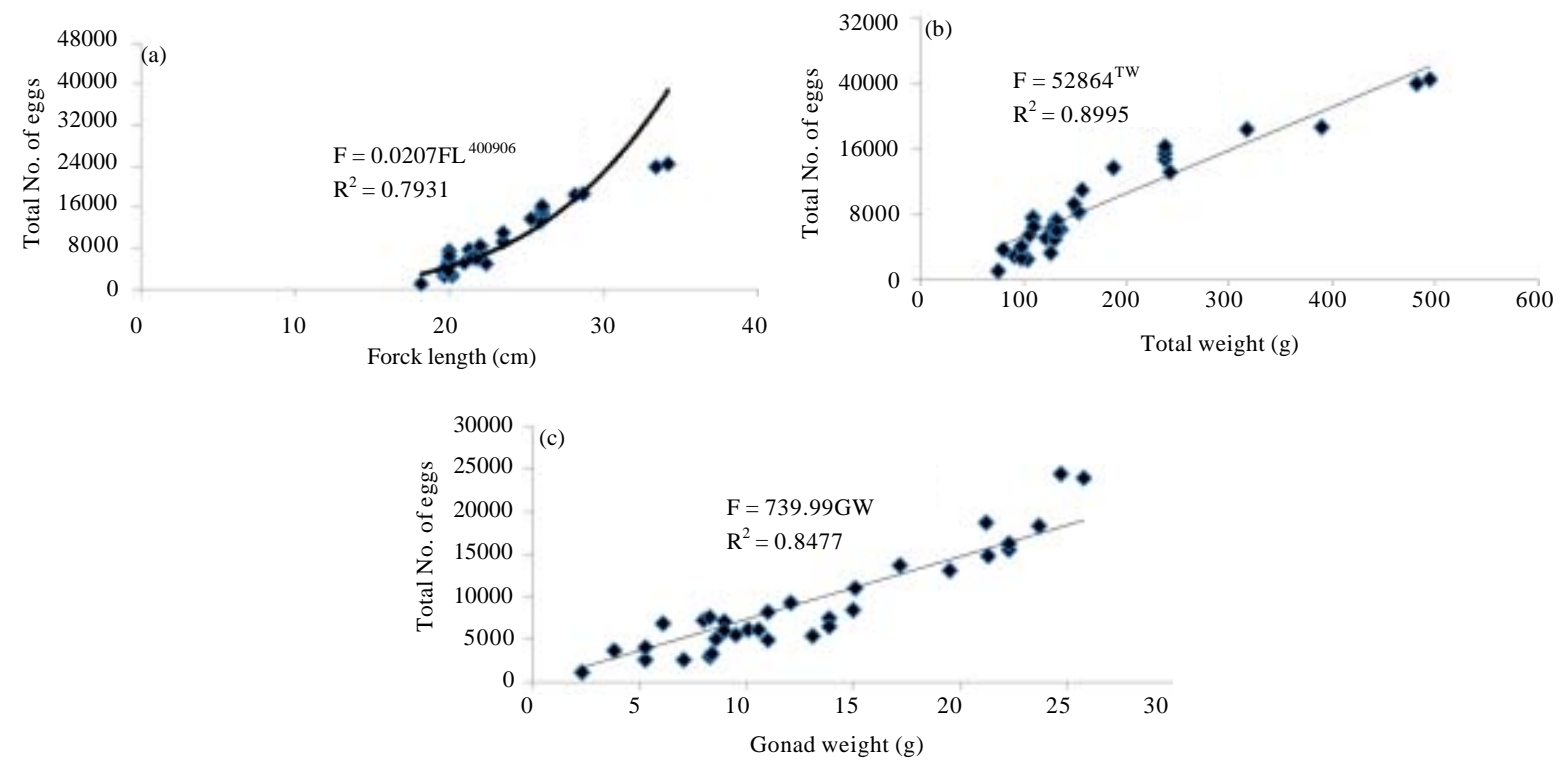

Fig. 4(a-c): Relationship between absolute (total) fecundity and fork length, total weight and gonad weight of L. intermedius in Infranz River
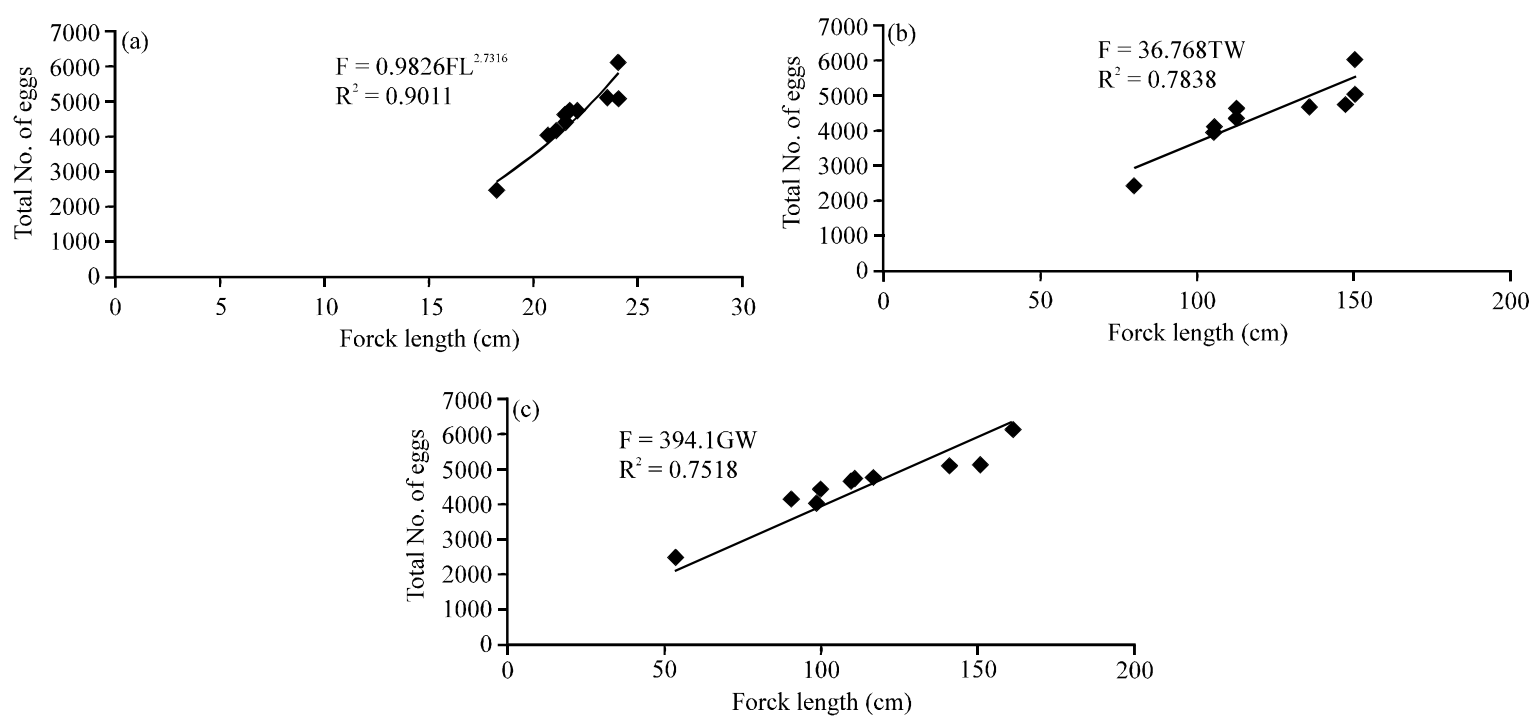

Fig. 5(a-c): Relationship between absolute (total) fecundity and fork length, total weight and gonad weight of L. brevicephalus in Infranz

Temporal segregation: Temporally the aggregation of the dominant Labeobarbus species migrating to Infranz river varies on the spawning season (July to November) in all sampling sites (Fig. 7). For instance L. brevicephalus was not found in all sampling sites during July. Labeobarbus nedgia was also found very rarely during July in site 3 and 4 . On the other hand, L. intermedius was absent in site 4 during November and $L$. tsanensis was not found in site 1, 2, 3 during November and in site 2 and 3 during July. 


\section{J. Fish. Aquat. Sci., 8(6): 627-642, 2013}

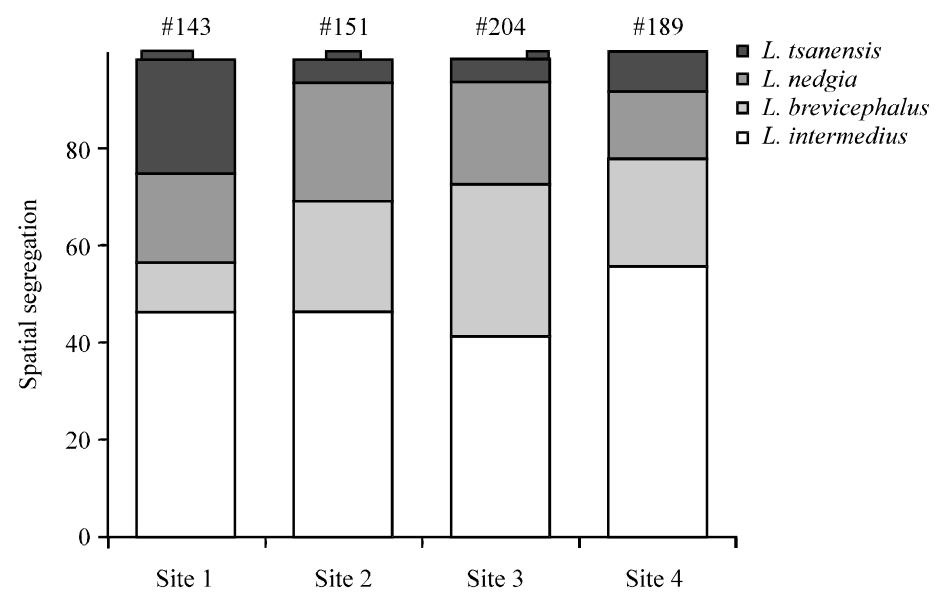

Fig. 6: Contribution of Labeobarbus species at different sampling sites in Infranz River during the sampling months (July-November)
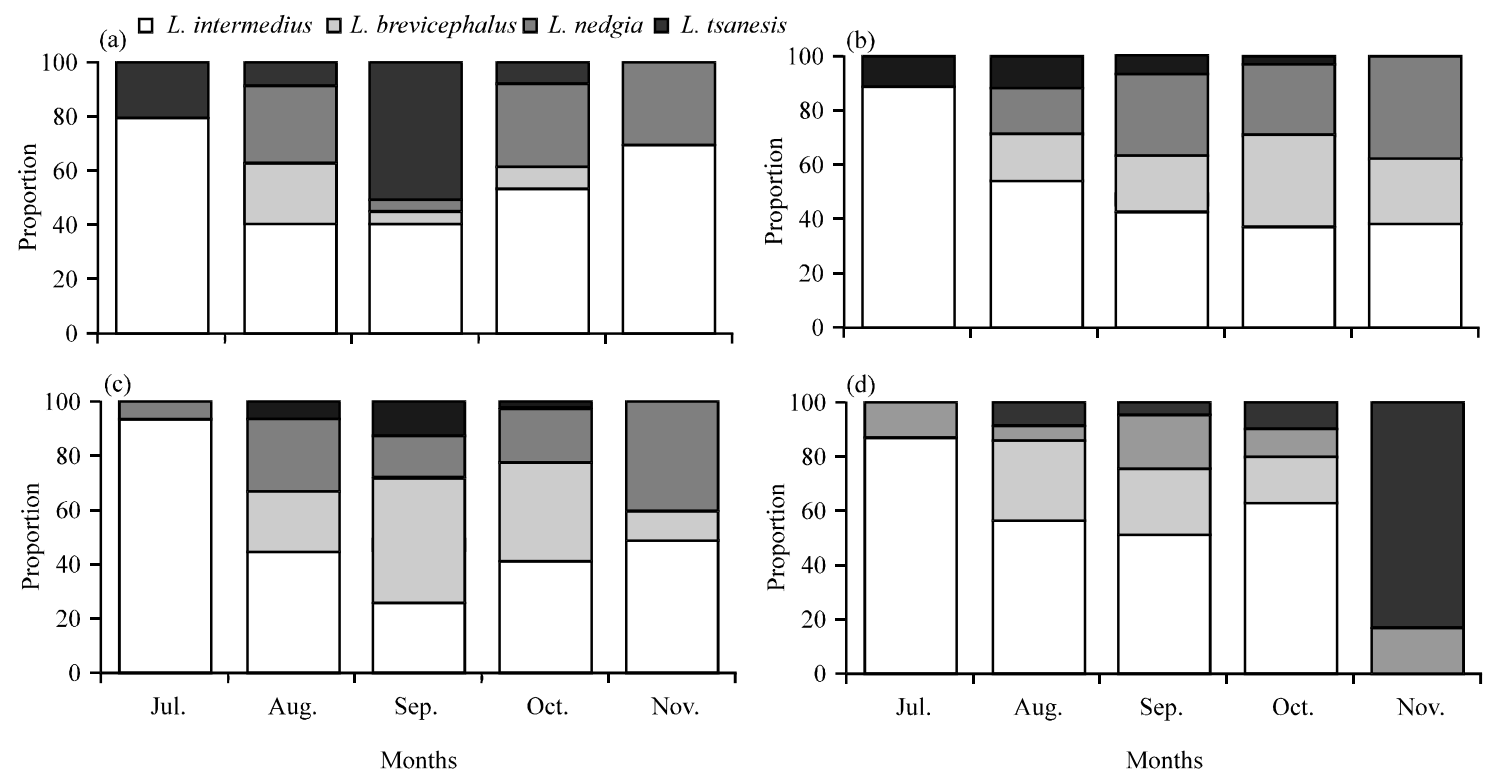

Fig. 7(a-d): Proportions of Labeobarbus species during the peak spawning season in all sampling sites as a function of time

Migration of the tropical freshwater fish to breeding grounds is mainly triggered by rainfall patterns and water level variations (Lowe-McConnell, 1975). The Labeobarbus species in Lake Tana also aggregate at river mouths to spawn in the rainy season (Nagelkerke and Sibbing, 1996; Dgebuadze et al., 1999; Palstra et al., 2004; De Graaf et al., 2005; Anteneh et al., 2008 and Gebremedhin et al., 2012). In this study, four Labeobarbus species (L. intermedius, L. brevicephalus, L. nedgia and $L$. tsanensis) aggregated at the river mouth of Infranz River starting from July to the end of September.

The aggregation patterns in the river mouth and migration patterns in the upstream sites during the spawning months are given in Fig. 8. Labeobarbus intermedius and L. tsanensis were the first species to aggregate in the river mouth starting from July and reached their peak in 

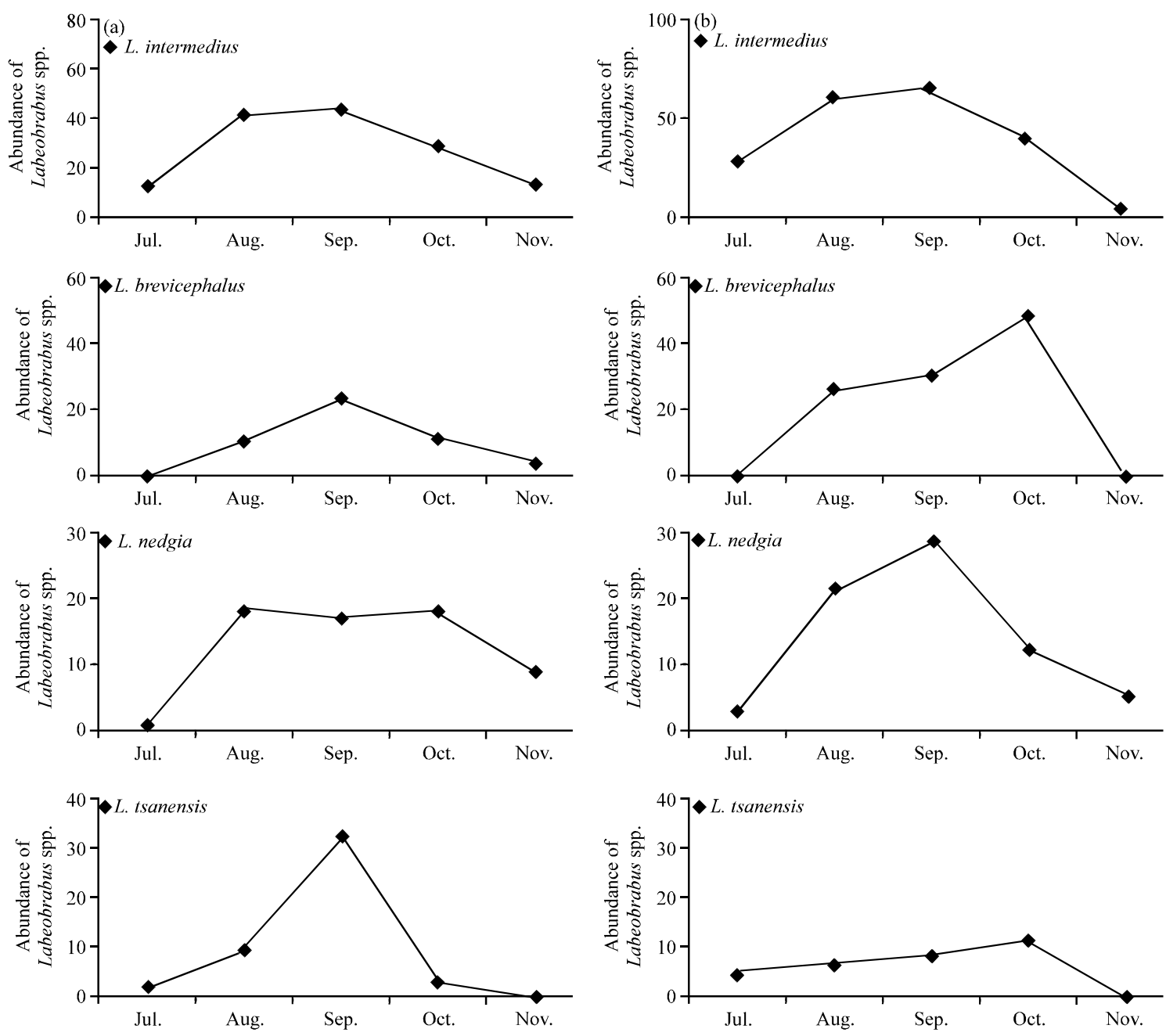

Fig. 8(a-b): Temporal variation in abundance of Labeobarbus species during the breeding season (July to November) in the (a) River mouth and (b) Upstream sites

September (Fig. 8a). Labeobarbus nedgia starts to aggregate in the river mouth in the late July and reached its peak in August. Labeobarbus brevicephalus was the last species to aggregate in the river mouth starting from August and reached its peak in September (Fig. 8a).

The first migrant to upstream sites were L. intermedius and L. tsanensis which start to ascend at the end of July, but their catch was higher in September and October, respectively (Fig. 8b). The last migrant was L. brevicephalus starting from end of August. Catch of L. brevicephalus reached its peak on October. All Labeobarbus species showed a declining pattern in catch from October to November which is the indication of the end of spawning period (Fig. 8b). The temporal segregation of the dominant Labeobarbus species migrating to Infranz River showed statistically significant difference $(p<0.001$, one way ANOVA).

\section{CONCLUSION}

Out of the total 952 fish specimens collected during the study period from all sampling sites, 8 species were belonging to the genus Labeobarbus and the other species were O. niloticus, 
C. gariepinus and $V$. beso. From the index of relative importance, L. intermedius was the most dominant species in all of the sampling sites in the river and the relationship between fork length and total weight of the dominant Labeobarbus species in Infranz River was curvilinear. Fulton's condition factor didn't significant variation for all of the dominant species during the peak and non-peak spawning season and by sex. Females were most numerous than males for the Labeobarbus species migrating to Infranz River and this is high in the peak spawning season. The chi-square test showed that there was significant difference between the number of females and males for L. intermedius and L. tsanensis however, it was not significantly different for L. brevicephalus and L. nedgia from the theoretical 1:1 ratio in Infranz River. From their monthly Gonado somatic index the peak spawning month was August to October.

Labeobarbus intermedius had both high number of eggs than L. brevicephalus and the relationship of the total eggs with fork length was curvilinear, but it was linear with total weight and gonad weight of the two species. Mainly four species (L. intermedius, L. brevicephalus, L. nedgia and L. tsanensis) aggregated at the river mouth. L. intermedius and L. tsanensis were the first species to aggregate at the river mouth however; L. brevicephalus was the last to aggregate in the river mouth. The first species to migrate to the upstream sites was L. intermedius and followed by L. tsanensis but the last migrant was L. brevicephalus.

\section{ACKNOWLEDGMENT}

First and foremost our praise goes to God, who has supported us to finish this study. Our warmest appreciation goes to Bahir Dar University (BDU) Graduate Program, Research and Community Service for all-round financial support, which was very fundamental to carry out this study without suffering. Thus, this work is not only the work of researchers, but also the funding agency i.e. Bahir Dar University too. We would like to express our gratitude to Asratu Wondie who assisted us in collecting the data.

\section{REFERENCES}

Al-Kholy, A.A., 1972. Aquatic resources of Arab countries: Alesco science monograph series. Arab League Education Cultural and Scientific Organization (ALECSO), Pages: 452.

Alekseyev, S.S., Dgebuadze, Y. Yu, M.V. Mina and A.N. Mironovsky, 1996. Small large barbs spawning in tributaries of Lake Tana: What are they? Folia Zool., 45: 85-96.

Ameha, A., 2004. The effect of birbira, Milletia ferruginea (Hochst.) Baker on some Barbus sp. (Cyprinidae, Teleostei) in Gumara river (Lake Tana), Ethiopia. M.Sc. Thesis, Addis Ababa University.

Anteneh, W., A. Getahun and E. Dejen, 2008. The lacustrine species of Labeobarbus of Lake Tana (Ethiopia) spawning at Megech and Dirma tributary rivers. SINET: Ethiop. J. Sci., 31: 21-28.

Bagenal, T.B. and F.W. Tesch, 1978. Age and Growth. In: Methods for Assessment of Fish Production in Fresh Water, Bagenal, T.B. (Ed.). Blackwell Scientific Publications, Oxford, UK., pp: 101-136.

Bagenal, T.B., 1978. Aspects of Fish Fecundity. In: Ecology of Freshwater Fish Production, Gerking, S.D. (Ed.). Wiley, Blackwell Scientific Publications, New York, pp: 75-101.

Berie, Z., 2007. Diversity, relative abundance and biology of fishes in beles and gelgel beles rivers, abay basin Ethiopia. M.Sc. Thesis, Addis Ababa University, Ethiopia.

Dadebo, E., G. Ahlgren and I. Ahlgren, 2003. Aspects of reproductive biology of Labeo horie Heckel (Pisces: Cyprinidae) in Lake Chamo, Ethiopia. Afr. J. Ecol., 41: 31-38. 
De Graaf, M., 2003. Lake Tana's piscivorous Barbus (Cyprinidae, Ethiopia): ecology, evolution, exploitation. Ph.D. Thesis, Wageningen University, Wageningen. The Netherlandas.

De Graaf, M., E. Dejen, J.W.M. Osse and F.A. Sibbing, 2008. Adaptive radiation of Lake Tana's Labeobarbus species flock (Pisces, Cyprinidae). Mar. Fresh Res., 59: 391-407.

De Graaf, M., E.D. Nentwich, J.W.M. Oss and F.A. Sibbing, 2005. Lacustrine spawning: Is this a new reproductive strategy among large African cyprinid fishes? J. Fish Biol., 66: 1214-1236.

De Graaf, M., M.A.M. Machiels, T. Wudneh and F.A. Sibbing, 2004. Declining stocks of Lake Tana's endemic Barbus species flock (Pisces; Cyprinidae): Natural variation or human impact? Biol. Conservat., 116: 277-287.

De Graaf, M., P.A.M. van Zwieten, M.A.M. Machiels, E. Lemma, T. Wudneh, E. Dejen and F.A. Sibbing, 2006. Vulnerability to a small-scale commercial fishery of Lake Tana's (Ethiopia) endemic Labeobarbus compared with African catfish and Nile tilapia: An example of recruitment-over fishing. Fish. Res., 82: 304-318.

Dgebuadze, Y.U., M.V. Mina, S.S. Alekseyev and A.S. Golubtsov, 1999. Observations on reproduction of the Lake Tana barbs. J. Fish Biol., 54: 417-423.

Dixon, B., L.A.J. Nagelkerke, F.A. Sibbing, E. Egberts and R.J.M. Stet, 1996. Evolution of MHC class II chain-encoding genes in the Lake Tana barbell species ?ock (Barbus intermedius complex). Immunogenetics, 44: 419-431.

Gebrekidane, W., 2010. Assessment of biodiversity and land use system of infraz riverine wetland in Lake Tane watershed M.Sc. Thesis, Bahir Dar University, Ethiopia.

Gebremedhin, S., M. Mingist, A. Getahun and W. Anteneh, 2012. Spawning migration of Labeobarbus sp. (PISCES: CYPRINIDAE) of Lake Tana to Arno-Garno river, Lake Tana sub basin, Ethiopia. SINET:Ethiop. J. Sci., 35: 95-106.

Getahun, A., E. Dejen and W. Anteneh, 2008. Fishery studies of Ribb River, Lake Tana Basin, Ethiopia. Ethiopian Nile Irrigation and Drainage Project Coordination Office: Final report E1573. Volume 2, Ministry of Water Resources, Addis Ababa, Ethiopia.

Hirpo, L.A., 2012. Food and feeding habits of Crucian carp (Carassius carassius) in Melkawakena reservoir, Ethiopia. Livestock Res. Rural Develop., Vol. 24,

Kolding, J., 1989. The fish resource of Lake Turkana and their environment. Ph.D. Thesis, University of Bergen, Norway.

Kolding, J., 1999. PASGEAR-A Data Base Package for Experimental or Artisanal Fishery Data from Passive Gears. An Introductory Manual. Dept. of Fisheries and Marine Biology, University of Bergen, Bergen, Norway, pp: 61.

Kornfield, I. and K.E. Carpenter, 1984. Cyprinids of Lake Lanao, Philippines: Taxonomic Validity, Evolutionary Rates and Speciation Scenarios. In: Evolution of Fish Species Flocks, Echelle, A.A. and I. Kornfield (Eds.). Orono Press, Maine, pp: 69-83.

Kruiswijk, C.P., T. Hermsen, J. van Heerwaarden, B. Dixon, H.F.J. Savelkoul and R.J.M. Stet, 2002. Different Modes of Major Histocompatibility Class Ia and Class IIb Evolution in the Lake Tana African Large Barb Species Flock. In: Evolution of Major Histocompatibility Genes in Cyprinid Fish: Molecular Analyses and Phylogenies, Kruiswijk, C.P. (Ed.). University of Wageningen, Wageningen, pp: 77-116.

Lowe-McConnell, R.H., 1975. Fish Communities in Tropical Freshwaters: Their Distribution, Ecology and Evolution. Longman, London, pp: 337.

MacGregor, J.S., 1957. Fecundity of the pacific sardine (Sardinops carerulea). Fish. Bull. U.S. Wildlife Serv., 17: 427-449. 
Marshal, B.E., 1995. Why is Limnothrissa miodon Such as a Successful Introduced Species and is there Anywhere Else we Should Put it? In: The Impact of Species Changes in Africa Lakes, Pitcher, T.J. and P.J.B. Hart (Eds.). Chapman and Hall, London, UK.

Matsuyama, M., S. Adachi, Y. Nagahama and S. Matsuura, 1988. Diurnal rhythm of oocyte development and plasma steroid hormone levels in the female red sea bream during the spawning season. Aquaculture, 73: 357-372.

Murdoch, T.B. and C. Martha, 1999. The Streamkeeper's Field Guide: Watershed Inventory and Stream Monitoring Methods. Adopt-A-Stream Foundation, Everett, WA., Pages: 296.

Nagelkerke, L.A.J. and F.A. Sibbing, 1996. Reproductive segregation among the large barbs (Barbus intermedius complex) of Lake Tana, Ethiopia: An example of in tralacustrine speciation? J. Fish. Biol., 49: 1244-1266.

Nagelkerke, L.A.J. and F.A. Sibbing, 2000. The large barbs (Barbus sp., Cyprinidae Teleostei) of Lake Tana (Ethiopia), with a description of a new species, Barbus ossensis. Neth. J. Zool., 2: $179-214$.

Nagelkerke, L.A.J., 1997. The barbs of Lake Tana, Ethiopia: Morphological diversity and its implications for taxonomy, trophic resource partitioning and fisheries. Ph.D. Thesis, Agricultural University Wageningen, The Netherlands.

Nagelkerke, L.A.J., F.A. Sibbing, J.G.M. Boogaart, E.H.R.R. Lammens and J.W.M. Osse, 1994. The barbs (Barbus sp.) of Lake Tana: A forgotten species ?ock? Environ. Biol. Fish., 39: 1-22.

Nelson, J.S., 1994. Fishes of the World. 3rd Edn., John Wiley and Sons Inc., New York, USA., ISBN: 9780471547136, pp: 234.

Oliva-Paterna, F.J., M.M. Torralva and C. Fernandez-Delago, 2002. Age, growth and reproduction of Cobitis paludica in a seasonal stream. J. Fish. Biol., 60: 389-404.

Palstra, A.P., M. de Graaf and F.A. Sibbing, 2004. Riverine spawning and reproductive segregation in a lacustrine cyprinid species flock, facilitated by homing? Anim. Biol., 54: 393-415.

Sadovy, Y. and D.Y. Shapiro, 1987. Criteria for the diagnosis of hermaphroditism in fishes. J. Copeia., 1: 136-156.

Sanyanga, R.A., 1996. Variation in abundance of Synodontis zambezensis (Pisces: Mockokidae) Peters 1852, in the shore fishery of Lake Kariba. Fish. Res., 26: 171-186.

Sibbing, F.A. and L.A.J. Nagelkerke, 2001. Resource partitioning by Lake Tana barbs predicted from ?sh morphometrics and prey characteristics. Rev. Fish Biol. Fish., 10: 393-437.

Skelton, P.H., D. Tweddle and P. Jackson, 1991. Cyprinids of Africa. In: Cyprinid Fishes, Systematics, Biology and Exploitation, Winfield, I.J. and J.S. Nelson (Eds.). Chapman and Hall, London, pp: 211-233.

Taylor, M.H. and E.P. Villoso, 1994. Daily ovarian and spawning cycles in weakfish. Trans. Am. Fish. Soc., 123: 9-14.

Tessema, A., M. Mingist and E. Dejen, 2012. Diversity, relative abundance and biology of fishes in Mille and Borkena Rivers, Awash Basin, Ethiopia. J Fish. Int., 7: 70-76.

Vijverberg, J., E. Dejen, A. Getahun and L.A.J. Nagelkerke, 2012. The composition of fish communities of nine Ethiopian lakes along a North-South gradient: Threats and possible solutions. Anim. Biol., 10.1163/157075611X618246. 